\title{
Editorial: Supporting, managing, \& sustaining creativity and cognition through technology
}

\section{Chien-Sing Lee*}

Graduate Institute of Network Learning Technology

National Central University, Taiwan

E-mail: cslee@cl.ncu.edu.tw

\section{Jie-Chi Yang}

Graduate Institute of Network Learning Technology

National Central University, Taiwan

E-mail: yang@cl.ncu.edu.tw

\section{Jimmy Secretan}

Korrelate Inc., USA

E-mail: jimmy@korrelate.com

\section{Pedro Branco}

engageLab, Department of Information Systems

University of Minho, Portugal

E-mail: pbranco@dsi.uminho.pt

\section{Cristina Sylla}

engageLab, Department of Information Systems

University of Minho, Portugal

E-mail: sylla@engagelab.org

*Corresponding author

\begin{abstract}
This special issue aims to present an overview of how creativity and cognition can be supported, managed and sustained through the use of technology. Three different roles of technology are presented. The first three papers highlight the potential of semi-automated creativity, the fourth paper how social media can be leveraged as a creativity platform and the fifth and final papers the use of technology-integrated intelligibility catchers and 3D technology as cognitive tools to enhance meaningful co-construction of new knowledge.

Keywords: Supporting; Managing; Sustaining; Creativity; Cognition; Technology

Biographical notes: Dr. Chien-Sing Lee is an Associate Professor in the Graduate Institute of Network Learning Technology, National Central
\end{abstract}


University, Taiwan. Her research interests revolve around creativity support tools, personalized learning, collaborative learning, games-based learning, mobile learning, ontology, data mining and knowledge management.

Jie-Chi Yang received his Ph.D. degree in Department of Human System Science from Tokyo Institute of Technology, Japan, in 2000. He is currently a Distinguished Professor of the Graduate Institute of Network Learning Technology at National Central University, Taiwan. His research interests include mobile learning, digital game-based learning, computer assisted language learning, and multimedia technologies.

Jimmy Secretan holds a $\mathrm{PhD}$ in Computer Engineering from UCF, where he was an NSF Graduate Research Fellow. He has published in the areas of creativity support tools, machine learning and privacy preserving data mining. $\mathrm{He}$ has chaired workshops about creativity support technologies at $\mathrm{CHI}$ and Creativity and Cognition. He originated the concept and led the team to create Picbreeder.org, a first of its kind collaborative evolutionary website. $\mathrm{He}$ currently works as Principal Scientist at Korrelate, Inc in Orlando, Florida, where he develops code run by millions of browsers and architects large scale, privacy-safe analytics systems for processing billions of records.

Dr. Pedro Branco is Assistant Professor at the Department of Information Systems, University of Minho where he is currently the director of the Master Program in Technology and Digital Art. He is working on several funded research projects focusing on diverse aspects of human-computer interaction, ranging from new educational interfaces for pre-school, to interactive systems that are aware of users' social signals. Throughout the Technology and Digital Art master program he works closely with students from a wide range of backgrounds developing interactive systems that explore a synergy of technology and aesthetics, exploring future directions for our interaction with technology.

Cristina Sylla is a researcher at engageLab, University of Minho. Her research interests focus on technology enhanced learning, user centered design and usability studies.

\section{Introduction}

In the 21st century, knowledge no longer exists in independent silos. Relevant and useful knowledge can be across disciplines; beyond expected boundaries. Hence, effective organizational learning requires efficient and effective tools, which enable the user to effectively seek, reconstruct and transform the information gathered into meaningful and novel knowledge.

The transformation of information into knowledge involves an iterative process. Learners need to design, prototype and test out alternative solutions by iteratively and collaboratively investigating, designing and redesigning goals that direct convergent and divergent search processes, processes/behaviours and representations of knowledge 
structures in relation to a systemic whole, to achieve more effective processes and outcomes (Kolodner, Crismond, Fasse, Gray, Holbrook, \& Puntembakar, 2003; Vattam, Goel, Rugaber, Hmelo-Silver, Jordan, Gray, \& Sinha, 2011).

Creative thinking thus adds the dimensions of generative design questioning, deep reasoning and synthesis to information discovery. By giving priority to divergent thinking above convergent thinking, generation of alternatives is likely to become richer. Ultimately, it is hoped that learners will have more ideas, have more categories of ideas, be more novel and more practical and most importantly, be intrinsically motivated and successful thinkers.

In view of the above, we turn our attention to how technology can support, create and sustain creativity and cognition. Undeniably, new technologies have quickly integrated themselves into the fabric of the creative process, for both professionals and novices alike. Hence, the role of technology in creativity should not be limited to taking over the rote and laborious tasks that the designer does not wish to do. Instead, supporting, creating and sustaining creativity and cognition through technology should contribute meaningfully towards all stakeholders be they designers, consumers, teachers or learners.

Considering the vast possibilities that creativity and cognition can be supported by technology, this special issue presents an emerging line of research focused on making the computer a more integral part of the creative process, i.e., where software acts more like a colleague and less like a servant. Three different roles of technology are presented. The first three papers highlight the potential of semi-automated creativity, the fourth paper the power of the social media as creativity platform and the fifth and final papers the use of semantic-oriented e-learning contracts (intelligibility catchers) and 3D virtual modeling as cognitive tools to enhance meaningful co-construction of new knowledge.

\section{Preview of papers}

Richard P. Gabriel, in his paper views software as more of a playful partner in the creative process. He takes advantage of online tools like Google and Bablefish for defamiliarization: a technique where creativity is encouraged by using unfamiliar language to transform the meaning of familiar situations. In one particularly vivid example, Gabriel uses a cycle of Babelfish translations to change the language of Robert Frost's famous poem, "Stopping by Woods on Snowy Evening." He transforms it from its familiar romance to a stark, otherworldly beauty. With this use of Web tools, we should never again let writer's block stop us.

In the second paper, Anthony McCaffrey and Lee Spector describe algorithmic manifestations of creativity enhancement techniques. These techniques are centered around the Obscure Feature Hypothesis, which asserts that if the properties of common designs and inventions are transposed to a feature space, that one can highlight unexplored areas of this space. By superimposing a semantic network on top of this design space, software can help users to navigate the space in unique ways, in order to generate more, higher quality solutions. McCaffrey and Spector even leverage this technique to create a clever new type of candle, which has found some commercial success.

In the third paper, Robert McGrath, Johan Rischau, and Alan B. Craig discuss an altogether new form of creative partnership, with machine as mind reader. The authors 
describe NeuroMaker, a fascinating device that directly connects an EEG sensor to a $\mathrm{CNC}$ router machine, turning the user's brain waves directly into physical designs. While the authors readily admit that right now, the patterns generated are not discernible from random ones by the end user, one can imagine how far this could be taken in the future. A whole new realm of possibility will open up when software can respond to our creative process on a direct level.

The potential of semi-automated creativity has only begun to be harnessed. Yet, in an age where so much is said about the power of the social networks, and what happens within the social networks, another exciting avenue for creative explorations has presented itself. Christian Wagner and Ling Jiang present an interesting overview on creativity support, discussing the power of a large unbounded "group" in social media. As the authors point out, the collective intelligence arising from a large number of behaviors in social media, e.g., searching, blogging, and browsing, is visible and available to serve the creativity process. They propose an approach drawing on collective intelligence for locating problems in need of creative solutions, generating creative ideas for identified problems, and evaluating those ideas. The authors discuss those processes in the context of the business environment, with special focus on new products. The discussion on this article intends to demonstrate that the dimensions of creativity, as defined by the authors: originality, implementability and purpose, can be enhanced due to the diversity, independency and decentralization of collectives in social media.

The fifth and final papers deal with co-construction of knowledge in formal and blended learning. In the fifth paper, Chris Stary and Georg Weichhart link e-learning contracts with semantic e-learning systems through a theoretically-grounded semanticoriented framework, Intelligibility Catchers. Its novelty lies in the semantics that associate parts of the learning process with the overall learning process structure through metadata, enabling the discovery of the domain's underlying model. The inclusion of semantics results in more efficient searching and sharing of learning content, more effective context-sensitive feedback loops and ontological specifications of various possible learning paths. Furthermore, functions such as filter enables selection and arrangement of learning contents whereas views provide different views at the various stages of knowledge generation and sharing.

In the final paper, Yanqi Yang, Linkun Zhang, and Susan Bridges hope to extend the affordances of blended learning in an inquiry-based curriculum by providing additional 3D resources for case-based discussions. These case-based discussions apply PBL knowledge to solve authentic clinical cases. Findings indicate that students perceive the 3D models as user-friendly. Furthermore, the manipulation, measurement and assessment of the 3D models enable better understanding, which subsequently contribute towards positive perceptions towards the possibility of individual and co-construction of knowledge.

\section{Conclusions}

These papers challenge our notions of how software can bolster creativity support. There is further room for exploring semi-automated creativity, the phenomenon and relevance of social media, semantic-oriented self-managed learning and technology-enhanced 3D tools to support and leverage the creative process. We look forward to ushering in software as a creative peer and hope that you will join us in this adventure. 


\section{References}

Kolodner, J. L., Crismond, D., Fasse, B., Gray, J., Holbrook, J., \& Puntembakar, S. (2003). Putting a student-centered learning by design TM curriculum into practice: Lessons learned. Journal of the Learning Sciences, 12(4), 495-547.

Vattam, S. V., Goel, A. K., Rugaber, S., Hmelo-Silver, C. E., Jordan, R., Gray, S., \& Sinha, S. (2011). Understanding complex natural systems by articulating structurebehavior-function models. Educational Technology \& Society, 14(1), 66-81. 